\title{
Protection against Vibrio alginolyticus in crimson snapper Lutjanus erythropterus immunized with a DNA vaccine containing the ompW gene
}

\author{
Shuang-Hu Cai ${ }^{1,2,3}$, Yi-Shan Lu ${ }^{1,2,3}$, Ji-Chang Jian ${ }^{1,2,3}$, Bei Wang ${ }^{1,2,3}$, \\ Yu-Cong Huang ${ }^{1,2,3}$, Ju-Fen Tang ${ }^{1,2,3}$, Yu Ding ${ }^{1,2,3}$, Zao-He Wu $\mathrm{W}^{2,3,4, *}$ \\ ${ }^{1}$ Fisheries College, Guangdong Ocean University, Zhanjiang 524088, PR China \\ ${ }^{2}$ Guangdong Provincial Key Laboratory of Pathogenic Biology and Epidemiology for Aquatic Economic Animals, \\ Zhanjiang 524088, PR China \\ ${ }^{3}$ Key Laboratory of Control for Diseases of Aquatic Economic Animals of Guangdong Higher Education Institutes, \\ Zhanjiang 524088, PR China \\ ${ }^{4}$ Zhongkai University of Agriculture and Engineering, Guangzhou 510225, PR China
}

\begin{abstract}
The outer membrane proteins of Vibrio alginolyticus play an important role in the virulence of the bacterium and are potential candidates for vaccine development. In the present study, the ompW gene was cloned, expressed and purified. A DNA vaccine was constructed by inserting the ompW gene into a pcDNA plasmid. Crimson snapper Lutjanus erythropterus (Bloch) were injected intramuscularly with the recombinant plasmid pcDNA-ompW. The expression of the DNA vaccine was detected in gill, head kidney, heart, liver, spleen and injection site muscle of crimson snapper by RT-PCR 7 and $28 \mathrm{~d}$ post-vaccination. The ELISA results demonstrated that the DNA vaccine produced an observable antibody response in all sera of the vaccinated fish. In addition, crimson snapper immunized with the DNA vaccine showed a relative percentage survival (RPS) of $92.53 \%$, indicating effective protection against $V$. alginolyticus infection.
\end{abstract}

KEY WORDS: Vibriosis · Vaccination · Recombinant plasmid · Outer membrane protein · pcDNA · Aquaculture

Resale or republication not permitted without written consent of the publisher

\section{INTRODUCTION}

Vibriosis is an important disease causing high mortality in marine aquatic animals (Austin 1984). Vibrio alginolyticus is a Gram-negative bacterium of the family Vibrionaceae and is one of the major Vibrio pathogens endangering the aquaculture of marine animals in the coastal provinces of south China (Cai et al. 2007, Liang et al. 2011). The commercially important crimson snapper Lutjanus erythropterus (Bloch) is widely distributed throughout the Indian Ocean and the tropical parts of the western Pacific Ocean, ranging from India through the entire Malay Archipelago to China, the Philippines, and Australia (Zhang et al. 2006). L. erythropterus is considered to be a good species for aquaculture because of its robustness in heavily populated conditions and its rapid growth at elevated temperatures. Cultured $L$. erythropterus suffered serious production losses due to V. alginolyticus in China (Cai et al. 2010).

Control of vibriosis through antimicrobial treatment is not always successful and could be hazardous for the environment since resistant bacteria may be selected and the resistance transferred to aquatic animal or human pathogens. Therefore, it is essential to develop alternative effective prophylaxis against Vibrio infections. Compared with antimicrobial treatment, vaccination is a safer strategy for preventing vibriosis (Khushiramani et al. 2007, Cai et al. 2010). However, due to the diversity of the pathogens 
and their serotypes, progress in the development of vaccines against vibriosis has been slow. Therefore, more effort is required to develop a safe and effective vaccine (Sommerset et al. 2005, Li et al. 2010b).

Recently, DNA vaccines composed of plasmids equipped with a eukaryotic expression cassette have proven promising against viral or bacterial infections in fish, including infectious hematopoietic necrosis virus, viral haemorrhagic septicaemia virus, Aeromonas veroni, Vibrio anguillarum, V. harveyi and V. parahaemolyticus (Boudinot et al. 1998, Corbeil et al. 1999, Vazquez-Juarez et al. 2005, Kumar et al. 2007, Hu \& Sun 2011, Liu et al. 2011).

Outer membrane proteins (OMPs) are important for adhesion to host cells and are highly immunogenic bacterial components. They are easily recognized as foreign substances by the host's immunological defence system (Qian et al. 2007, Li et al. 2010a) and some studies have emphasized the role of OMPs of pathogenic bacteria in protective antigenicity because of their exposed epitopes on the cell surface (Karalus \& Murphy 1999). With regard to Vibrio species, attention has been paid to several OMPs such as OmpW, OmpK, OmpU and OmpV. The OmpW is a member of the small molecular OMP family of Gram-negative bacteria, and is involved in transportation of small hydrophobic molecules across the bacterial outer membrane (Hong et al. 2006, Touw et al. 2010).

The OmpW of Vibrio alginolyticus has been described as a 214 amino acid protein with a predicted molecular weight of $23.3 \mathrm{kDa}$ (Qian et al. 2007), and its gene found on chromosome II. It is likely to play an important role in bacterial physiology, contributing to the survival of $V$. alginolyticus within the host as well as in the wider environment (Nandi et al. 2005). OmpW is a highly conserved membrane protein in Vibrio species, and polyclonal antibody raised against recombinant OmpW from $V$. parahaemolyticus recognized the OmpW homologues from other strains of Vibrio species in immunoblotting studies (Qian et al. 2007). Therefore, OmpW could be a shared antigen among Vibrio species (Ma et al. 2011). Several reports have shown that vaccines consisting of OMPs can induce high protective immunity (Zhang et al. 2007, Cai et al. 2010). Therefore, OMPs are particularly attractive as vaccine candidates.

In the present study, we cloned the ompW gene from Vibrio alginolyticus and constructed a recombinant plasmid, pcDNA-ompW. This was used to immunize crimson snapper to explore the potential application of the ompW gene as a DNA vaccine candidate.

\section{MATERIALS AND METHODS}

\section{Extraction of genomic DNA}

Vibrio alginolyticus strain HY9901 was isolated from diseased mari-cultured crimson snapper Lutjanus erythropterus (Bloch) in Zhanjiang, China. The isolate was preserved in tryptone soya broth (Huangkai) supplemented with $2 \% \mathrm{NaCl}$ and $20 \%$ glycerol at $-80^{\circ} \mathrm{C}$. The culture was retrieved on tryptone soya agar (Huangkai) plates supplemented with $2 \% \mathrm{NaCl}$ and incubated at $28^{\circ} \mathrm{C}$. Genomic DNA was extracted using the MiniBEST Bacterial Genomic DNA Extraction Kit (Takara).

\section{Expression and purification of the recombinant OmpW}

The primers were designed based on the ompW gene sequence of Vibrio alginolyticus cloned by our laboratory (GenBank accession no. GQ891116). The sense primer, omp $W$-F1, was 5'-CGC CAT ATG AAA AAA ACA ATC TGC AGT CTA GC-3', corresponding to the ompW sequence from nucleotide 1 (the coding sequence starts at nucleotide 1) and containing an NdeI restriction site (underlined). The antisense primer, omp $W$-R1, was 5'-CCG CTC GAG GAA CTT GTA ACC GCC GCT GAT-3', corresponding to the ompW sequence from nucleotides 621 to 642 (the coding sequence ends at nucleotide 645) and containing an XhoI restriction site. The stop codon TAA was deleted in the ompW-R1 primer. Genomic DNA from $V$. alginolyticus strain HY9901 was used as the template in PCR. The PCR was performed in $25 \mu$ l of reaction mixture which contained $1 \times$ standard PCR reaction buffer (Takara), 50 ng of genomic DNA, $100 \mathrm{pmol} \mathrm{l}^{-1}$ of each primer, $200 \mu \mathrm{mol} \mathrm{l^{-1 }}$ of each deoxynucleoside triphosphate (Takara) and $1.5 \mathrm{U}$ of Ex Taq DNA polymerase (Takara). The amplification was carried out as follows: 5 min at $94^{\circ} \mathrm{C} ; 30$ cycles of $45 \mathrm{~s}$ at $94^{\circ} \mathrm{C}, 45 \mathrm{~s}$ at $58^{\circ} \mathrm{C}, 90 \mathrm{~s}$ at $72^{\circ} \mathrm{C}$; then $10 \mathrm{~min}$ at $72^{\circ} \mathrm{C}$ for further extension. The PCR product was cloned into the pMD18-T plasmid (Takara) and then sequenced by Shanghai Sangon Biological Engineering Technology and Services (SSBETS). The sequence was used to perform a BLAST search in GenBank, then multiple alignment and similarity analysis was carried out using the CLUSTAL X program (Thompson et al. 1997).

To construct an expression vector for ompW, the purified PCR product and the expression vector pET21a (Novagen) were digested with NdeI and 
XhoI and ligated together. pET21a-ompW was constructed by inserting the DNA fragment containing the ompW gene open reading frame without a stop codon into the $5^{\prime}-N d e I$ and $3^{\prime}$-XhoI sites of pET21a in-frame with the 6-histidine (His) tag. The 6-His-tagged protein can be purified using a $\mathrm{Ni}^{2+}$-iminodiacetic acid (IDA) Sepharose affinity column. The promoter and coding region of the recombinant pET21a-omp $W$ vector was confirmed by DNA sequencing and the vector was transformed into E. coli BL21 (DE3) for expression. The E. coli BL21 (DE3) cells containing pET21a-ompW were cultivated and induced with $1 \mathrm{mM}$ isopropylthio- $\beta$-D-galactoside (IPTG) in Luria-Bertani broth (LB; Huangkai) containing $50 \mathrm{mg} \mathrm{ml}^{-1}$ kanamycin at $37^{\circ} \mathrm{C}$. Then $100 \mathrm{ml}$ of the induced bacterial culture was centrifuged at $12000 \times g$ for $10 \mathrm{~min}$ at $4^{\circ} \mathrm{C}$ and the pellet was re-suspended in $15 \mathrm{ml}$ of $\mathrm{pH} 7.4$ lysis buffer $(20 \mathrm{mM}$ phosphate-buffered saline [PBS], $0.5 \mathrm{M} \mathrm{NaCl}$ and $8 \mathrm{M}$ urea). The cell suspension was sonicated and the lysed mixture was centrifuged at $12000 \times g$ for $10 \mathrm{~min}$ at $4^{\circ} \mathrm{C}$. Then the supernatant was collected and filtered through a $0.22 \mu \mathrm{m}$ spin filter (Ultrafree-MC; Millipore). The filtered supernatant was loaded into a $\mathrm{Ni}^{2+}$-IDA Sepharose affinity column. The recombinant OmpW was purified according to the manufacturer's instructions and analysed by sodium dodecyl sulphate polyacrylamide gel electrophoresis (SDS-PAGE).

\section{Construction and preparation of DNA vaccines}

Primers (omp $W$-F2: 5'-CGG AAT TCA TGA AAC AGG GTG ACT TCG TTC TTC GT-3'; ompW-R2: 5'CCG CTC GAG CTA CTT GTA ACC GCC GCT GAT-3') containing specific restriction sites (ECoRI / XhoI, underlined) were designed to amplify the omp W gene for cloning into a eukaryotic expression vector. Genomic DNA from Vibrio alginolyticus strain HY9901 was used as the template in PCR. The PCR reaction mixtures were comprised as described above. The amplification was carried out as follows: $5 \mathrm{~min}$ at $94^{\circ} \mathrm{C}$; 30 cycles of $45 \mathrm{~s}$ at $94^{\circ} \mathrm{C}, 45 \mathrm{~s}$ at $63^{\circ} \mathrm{C}$, $60 \mathrm{~s}$ at $72^{\circ} \mathrm{C}_{\text {; }}$ then $10 \mathrm{~min}$ at $72^{\circ} \mathrm{C}$ for further extension. The PCR product was purified using the QIAquick-spin PCR Purification Kit (Qiagen), cloned into the eukaryotic expression vector pcDNA3.1 (Invitrogen), and transformed into E. coli DH5 $\alpha$ grown in LB media at $37^{\circ} \mathrm{C}$. Recombinant clones were selected by ampicillin resistance and confirmed by restriction analysis of recombinant plasmids, and then sequenced at SSBETS. pcDNA-omp $W$ was prepared on a large scale in E. coli DH5 $\alpha$ grown in LB media at $37^{\circ} \mathrm{C}$ and purified using PureLink ${ }^{\mathrm{TM}}$ HiPure Plasmid Filter Purification Kits (Invitrogen). The purified pcDNA-omp $W$ plasmid was suspended in PBS at a final concentration of $0.1 \mathrm{mg} \mathrm{ml}^{-1}$ and stored at $-20^{\circ} \mathrm{C}$ until use.

\section{Preparation of antiserum against the pcDNA-omp $W$ vaccine and western blot analysis}

Antiserum against the pcDNA-omp $W$ was raised in New Zealand white rabbits Oryctolagus cuniculus by means of subcutaneous injection of $0.1 \mathrm{ml}$ pcDNAompW $\left(0.1 \mathrm{mg} \mathrm{ml}^{-1}\right)$. All rabbits were boosted $4 \mathrm{wk}$ later with the same antigen preparations. The rabbits were bled $4 \mathrm{wk}$ after the booster injection, and the blood was clotted at room temperature for $1 \mathrm{~h}$ and then stored at $4^{\circ} \mathrm{C}$ overnight. The separated antiserum obtained by centrifugation was stored at $-70^{\circ} \mathrm{C}$ until use. Crude OMPs of Vibrio alginolyticus strain HY9901 were prepared according to Cai et al. (2010). The crude OMPs, recombinant OmpW, total protein of induced recombinant E. coli BL21 (DE3) harbouring pET21a-omp $W$, total protein of noninduced recombinant $E$. coli BL21 (DE3) harbouring pET21a-omp $W$ and the total protein of induced $E$. coli BL21 (DE3) were electrophoresed by SDS-PAGE on a $5 \%$ stacking gel and $15 \%$ separating gel under denaturing conditions. The proteins were electrically transferred from the gel to nitrocellulose paper using a semi-dry apparatus (Bio-Rad). The sera from rabbits vaccinated with pcDNA-omp $W$ were used as primary antibody at a 1:100 dilution. Non-immunized rabbit sera were used as primary antibody in the negative control. The secondary antibody was peroxidase-conjugated goat-anti-rabbit IgG (Sigma) used at a 1:5000 dilution. The antibody-bound proteins were then visualized by $3,3^{\prime}$-diaminobenzidine (DAB).

\section{Vaccination}

Healthy crimson snapper confirmed free of disease and weighing approximately $50 \mathrm{~g}$ were divided into 3 groups (100 fish in each group) for vaccination. Every group was kept in a $1000 \mathrm{l}$ tank with fresh running water at $25^{\circ} \mathrm{C}$ and fed to satiation daily with commercial dry pellets. The fish were allowed to acclimatise for $14 \mathrm{~d}$ before vaccination. In the test 
group, fish were injected intramuscularly with $0.1 \mathrm{ml}$

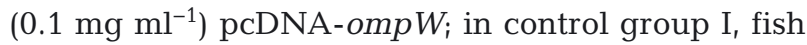
were injected intramuscularly with $0.1 \mathrm{ml}(0.1 \mathrm{mg}$ $\mathrm{ml}^{-1}$ ) pcDNA3.1; in control group II, fish were injected intramuscularly with $0.1 \mathrm{ml}$ PBS.

\section{Detecting expression of the ompW gene by RT-PCR}

Total RNA was extracted from individual tissues including gill, head kidney, heart, liver, spleen and injection site muscle from 6 fish from each group, at 7 and $28 \mathrm{~d}$ post-vaccination with Trizol reagent (Invitrogen). Genomic DNA was removed using the DNAfree $^{\mathrm{TM}}$ DNase Treatment and Removal Kit (Ambion). RNA concentration was measured with a spectrophotometer (NanoDrop Technologies). RNA was reverse transcribed into cDNA and amplified using the OneStep RT-PCR Kit (Qiagen) according to the manufacturer's instructions and using the primers ompWF3 (5'-CAC CAA GTG TTT TCG CTC AT-3') and omp $W$-R3 (5'-CTG CTT TGT AAG TTG CTT CTG T3'). RT-PCR was performed with a Bio-Rad C1000 thermal cycler using the following thermocycling conditions for the $\mathrm{PCR}$ reaction: denaturation for $5 \mathrm{~min}$ at $95^{\circ} \mathrm{C}, 30$ amplification cycles of $30 \mathrm{~s}$ at $95^{\circ} \mathrm{C}$, $30 \mathrm{~s}$ at $58^{\circ} \mathrm{C}, 30 \mathrm{~s}$ at $72^{\circ} \mathrm{C}$; then $10 \mathrm{~min}$ extension at $72^{\circ} \mathrm{C}$. The amplified fragments were sequenced by SSBETS.

\section{Analysis of specific antibody levels}

During 10 wk post-vaccination, 6 fish from each treatment group were assayed weekly for OmpWspecific antibodies in serum by enzyme-linked immunosorbent assay (ELISA). For this, 96-well plates were coated using $100 \mu \mathrm{l}\left(10 \mu \mathrm{g} \mathrm{ml}^{-1}\right)$ of the purified recombinant OmpW. Fish serum samples in 2-fold serial dilutions $\left(2^{0}\right.$ to $\left.2^{16}\right)$ were added to the microplate, which had been blocked with $2 \%$ BSA. Antibody binding to the antigen was detected using rabbit anti-crimson snapper IgM antibodies at a 1:500 dilution. Preparation of rabbit anti-crimson snapper IgM antibodies was carried out according to Cai et al. (2013). Plates were incubated with horseradish peroxidase-conjugated goat anti-rabbit IgG at a 1:1000 dilution. The reaction was developed with the 3,3,5,5-tetramethylbenzidine substrate and $\mathrm{H}_{2} \mathrm{O}_{2}$, and stopped with $2 \mathrm{M} \mathrm{H}_{2} \mathrm{SO}_{4}$. Optical density was measured at $450 \mathrm{~nm}$ using a microplate reader ( $\mathrm{QQuant}$; BioTek).

\section{Bacterial challenge experiments}

At 49 d post-immunization, 69, 72 and 72 fish of the vaccinated, control I and control II groups, respectively, were anaesthetized and challenged by intramuscular injection with $0.1 \mathrm{ml}$ bacterial suspension $\left(1 \times 10^{7}\right.$ colony-forming units $\left.\mathrm{ml}^{-1}\right)$ of Vibrio alginolyticus strain HY9901 (Kumar et al. 2007). Fish that died during the course of the challenge were autopsied to determine the cause of death and to detect the presence of $V$. alginolyticus in the tissues by bacterial culture in thiosulphate citrate bile salts-sucrose agar. Relative percentage survival (RPS) was calculated from the cumulative mortalities ( $M_{\mathrm{vac}}$ in vaccinated fish; $M_{\text {unvac }}$ in unvaccinated control fish) using:

$$
\operatorname{RPS}=\left[1-\left(M_{\mathrm{vac}} / M_{\text {unvac }}\right)\right] \times 100 \%
$$

\section{Statistical analysis}

Data are expressed as mean \pm SD. A statistical analysis was performed to assess serum antibody levels and mortality for significance $(p<0.05)$ using 1-way ANOVA (Kumar et al. 2007). Probabilities of 0.05 or less were considered statistically significant.

\section{RESULTS}

\section{Cloning, expression and purification of recombinant OmpW}

A 657 bp fragment was obtained from genomic DNA of Vibrio alginolyticus strain HY9901 by PCR amplification. The fragment contained an open reading frame (ORF) of 645 nucleotides which encodes 214 amino acids with a deduced molecular mass of $23.47 \mathrm{kDa}$. The nucleic acid sequence similarities with ompW of Vibrio sp. Ex25 (GenBank accession no. CP001806), V. parahaemolyticus RIMD 2210633 (GenBank accession no. BA000032) and Photobacterium damselae (GenBank accession no. DQ251175) were 96, 92 and 92\%, respectively. The amino acid sequence similarities with the proteins of Vibrio sp. Ex25, V. parahaemolyticus RIMD 2210633 and $V$. harveyi 1DA3 were 96, 92, and $91 \%$, respectively.

Sequencing revealed that the ompW gene was correctly cloned into the expression vector pET21a. The ompW gene was efficiently expressed following induction with IPTG and the recombinant protein was in inclusion body form. A novel protein band corresponding to $24 \mathrm{kDa}$ was detected in E. coli BL21 (DE3) harbouring the recombinant pET21a-ompW 
vector by SDS-PAGE (Fig. 1). The molecular weight of the recombinant protein was identical with that predicted from the nucleotide sequence of the ompW gene. After His-tag affinity chromatography, the expressed proteins were purified to a single band of the expected size, as confirmed by SDS-PAGE.

\section{Western blot analysis}

Following western blot analysis, a protein band was only recognized in the crude OMPs, purified recombinant OmpW and total protein of induced recombinant E. coli BL21 (DE3) harbouring pET21aompW (Fig. 2A, Lanes 1, 2 and 3). No band was found when western blotting was performed with the nonimmunized rabbit serum (Fig. 2B).

\section{Analysis of ompW gene expression}

RT-PCR was used to detect the distribution of the pcDNA-omp $W$ vector and/or expression of the ompW gene in different tissues of crimson snapper. The fragment, expected to be $525 \mathrm{bp}$ in length, was amplified from cDNA synthesized from the total RNA extracted from gill, head kidney, heart, liver, spleen and injection site muscle of fish vaccinated with pcDNA-omp $W$ on 7 and $28 \mathrm{~d}$ post-vaccination (Fig. 3). There was no band from the negative control groups I and II. Sequence analysis confirmed that the $525 \mathrm{bp}$ fragment was the partial ompW gene.

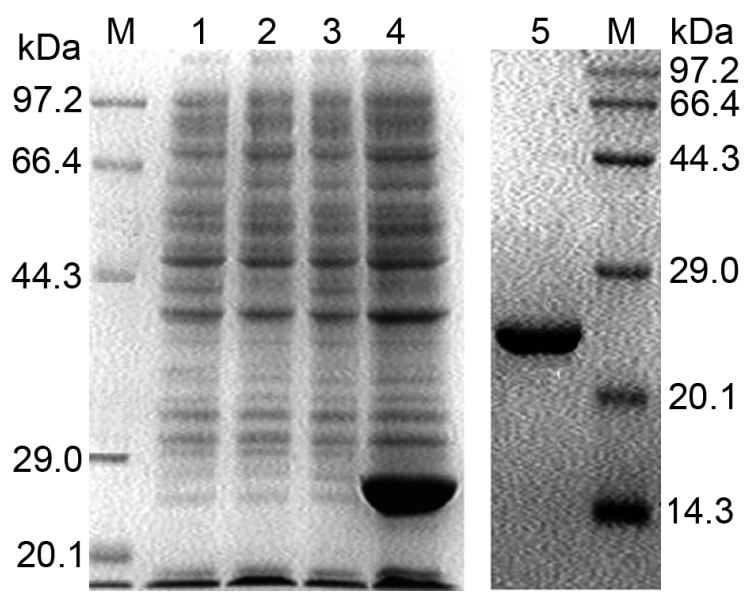

Fig. 1. SDS-PAGE analysis of the expression products of pET21a-ompW in E. coli BL21 (DE3). Lane $M$, protein marker; Lanes 1 to 4, total protein of recombinant $E$. coli BL21 (DE3) harbouring (Lane 1) pET21a, not induced, (Lane 2) pET21a, induced, (Lane 3) pET21a-ompW, not induced, and (Lane 4) pET21a-ompW, induced; Lane 5, purified recombinant OmpW

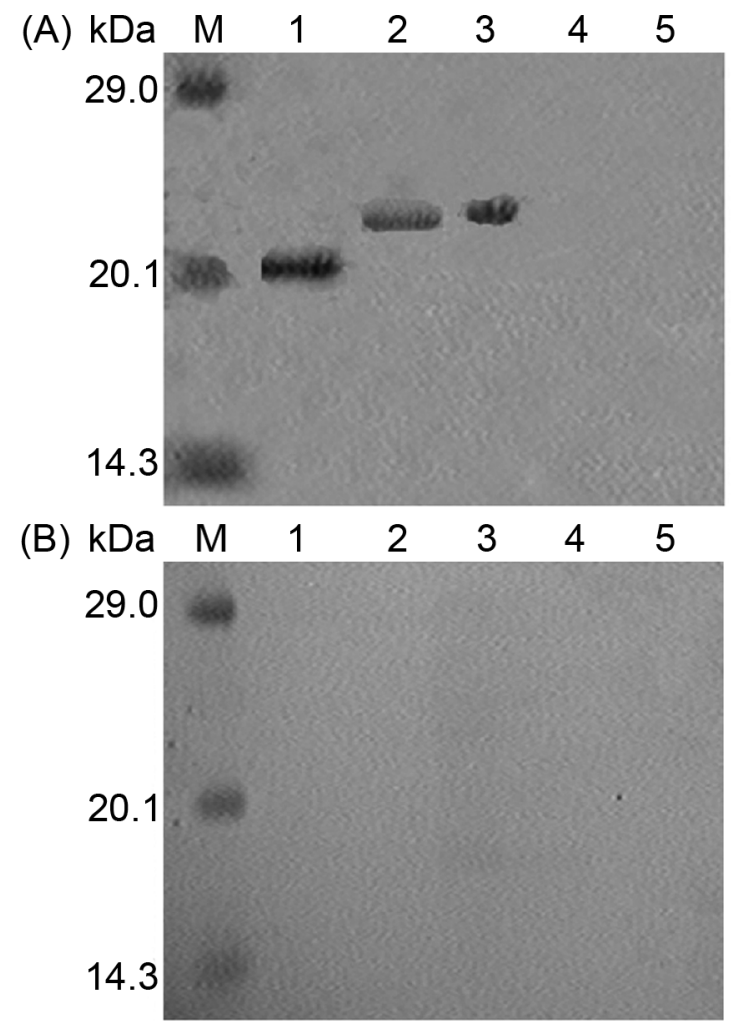

Fig. 2. Western blot analysis with (A) serum of rabbits immunized with pcDNA-omp $W$ and (B) non-immunized rabbit serum. Lane $M$, protein marker; Lane 1, crude outer membrane proteins of Vibrio alginolyticus strain HY9901; Lane 2, purified recombinant OmpW; Lanes 3 and 4, total protein of (Lane 3) induced and (Lane 4) non-induced recombinant E. coli BL21 (DE3) harbouring pET21a-ompW; Lane 5, total protein of induced E. coli BL21 (DE3)

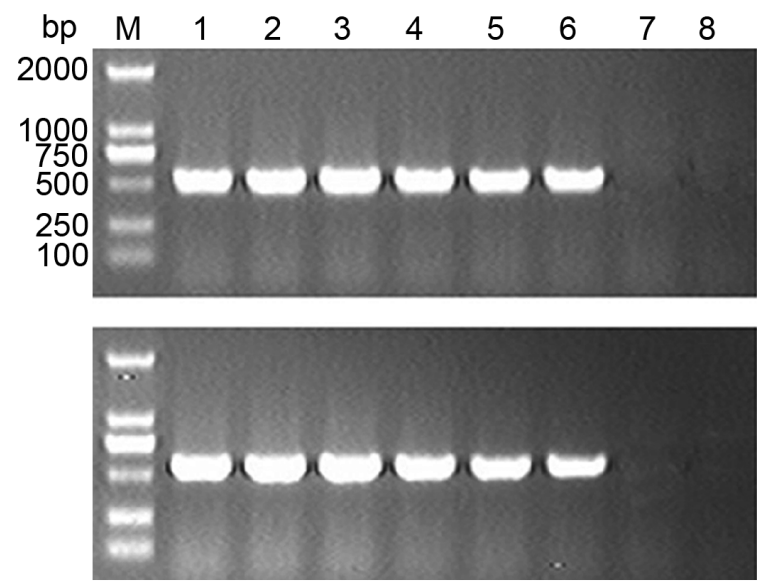

Fig. 3. Lutjanus erythropterus. Expression of the ompW gene in various fish tissues at (A) 7 and (B) $28 \mathrm{~d}$ post-vaccination by RT-PCR. Lane M, DL2000 marker; Lane 1, gill; Lane 2, head kidney; Lane 3, heart; Lane 4, liver; Lane 5, spleen; Lane 6, injection site muscle; Lane 7, injection site muscle of fish in negative control group $\mathrm{I}_{\text {; Lane }}$, injection site muscle of fish in negative control group II 


\section{Analysis of serum antibody levels}

The level of OmpW-specific serum antibodies in crimson snapper is shown in Fig. 4. The results indicated that an OmpW-specific antibody titre was detected in all sera of the vaccinated fish. During the 1 st to the 10 th week post-vaccination, $\log _{2}$ antibody titres in the sera of vaccinated groups all reached above 5.14, and the maximum reached 13.31, while that of control group I injected with the empty vector pcDNA3.1 was only 1.76 to 4.31 at all times, and that of control group II injected with PBS was 1.21 to

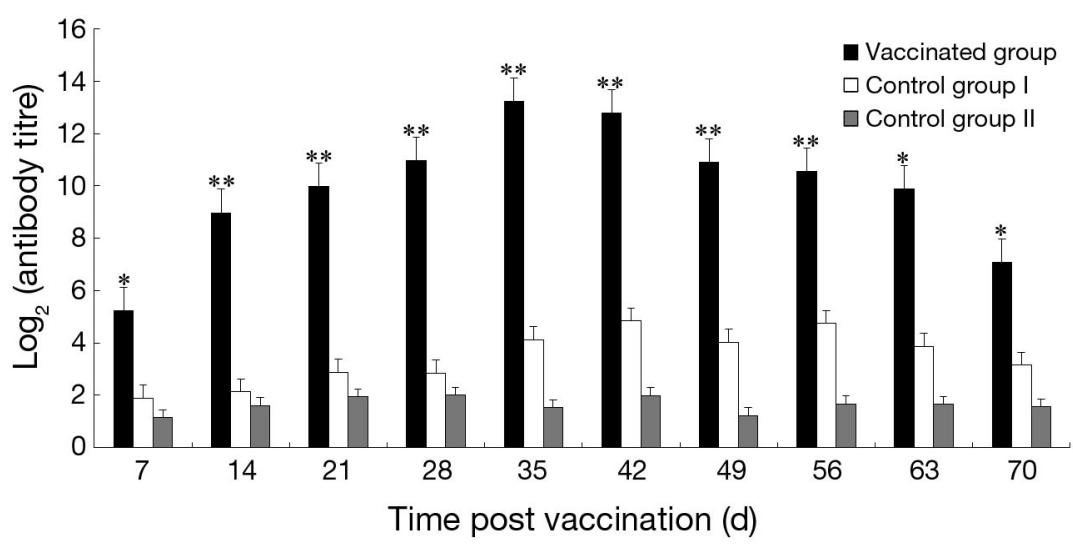

Fig. 4. Lutjanus erythropterus. Analysis of the OmpW-specific serum antibody

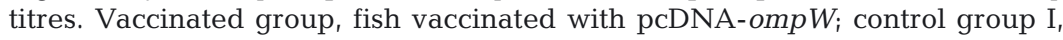
fish injected with the empty vector pcDNA3.1; control group II, fish injected with PBS. Each bar represents mean $\log _{2}$ value \pm SD of the highest dilution of the serum when $\mathrm{P} / \mathrm{N} \geq 2.1$, where $\mathrm{P}=$ optical density $\left(\mathrm{OD}_{492}\right)$ of the inspected serum, $\mathrm{N}=\mathrm{OD}_{492}$ of the negative serum. ${ }^{*} 0.01<\mathrm{p}<0.05,{ }^{* *} \mathrm{p}<0.01$

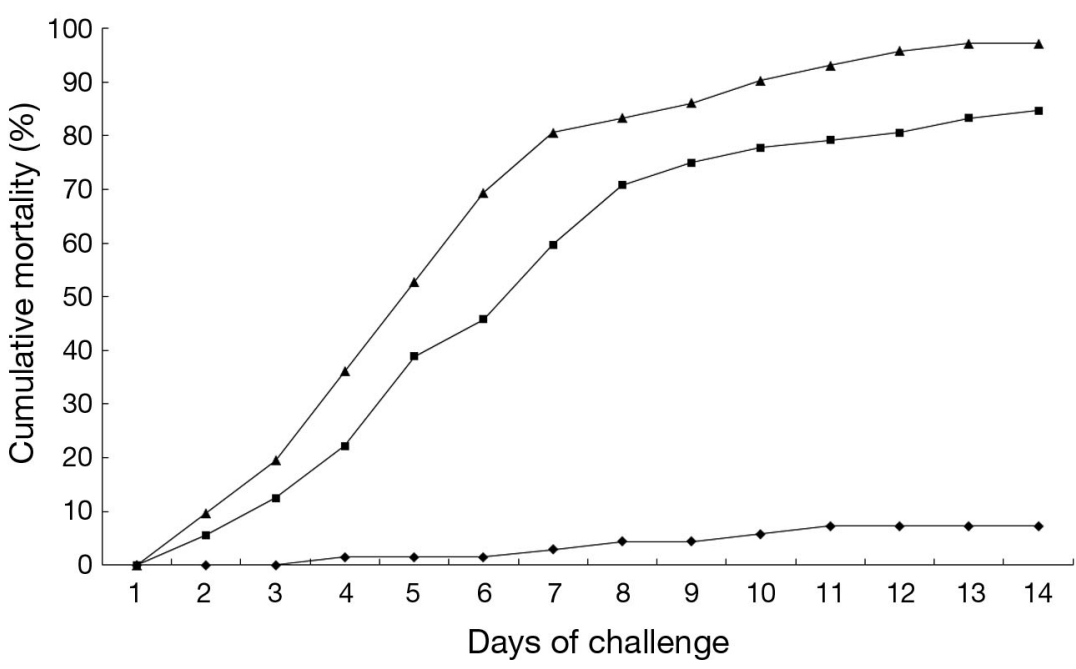

Fig. 5. Lutjanus erythropterus challenged with Vibrio alginolyticus strain HY9901. Cumulative mortality curves. ( ) Test fish vaccinated with pcDNAompW, ( $\mathbf{\square})$ control fish injected with the empty vector pcDNA3.1, ( $\mathbf{\Delta})$ control fish injected with PBS
1.97 at all times. Comparison of the means of $\log _{2}$ antibody titres between vaccinated and control groups revealed a statistically significant difference

e cumulative mortality of crimson snapper after enge with virulent Vibrio alginolyticus strain HY9901 is shown in Fig. 5. The fish immunized with the pcDNA-omp $W$ vaccine displayed a high level of protection. The fish mortality rate was significantly lower $(\mathrm{p}<0.01)$ in the vaccinated groups than in the control groups after challenge with virulent $V$. alginolyticus strain HY9901. The fish in the control group began to die 2 d post-challenge, with a sudden increase in the death rate between 3 and $8 d$, followed by a decrease until $14 \mathrm{~d}$ post-challenge. The dead fish in the control and vaccinated groups showed typical signs of vibriosis including anorexia, skin ulcers and necrosis of the tail fin and scales and no pathogen other than $V$. alginolyticus was isolated from dead fish. The RPS value for the pcDNA-omp $W$ vaccine was $92.53 \%$.

\section{DISCUSSION}

The outer membrane of Gramnegative pathogenic bacteria has an important role in adherence to host cells, uptake of nutrients from the host and subverting host defence mechanisms. The OMPs of these bacteria have been reported to play an important role during bacterial infection and induction of host immune response, and they are often able to induce neutralization antibodies that are bactericidal (Gatto et al. 2002), inducing cell-mediated immunity and inhibiting bacterial colonization in hosts (Sengupta et al. 1992). OMPs have shown even higher immunogenicity than inactivated whole cells, probably because chemicals such as formalin, used in whole cell prepara- 
tions, damage the structure of the bacterium's antigens (Prado et al. 2005). Some of the important attributes of a candidate molecule for vaccine development are that the candidate should be highly conserved among various members of the same genus, should be expressed on the surface of pathogens so that antigen-presenting cells can easily recognize them, and should be immunogenic (Karlsen et al. 2011). The BLAST results showed that the sequence of $o m p W$ is well conserved among different Vibrio species. This is one of the important reasons that OMPs are particularly attractive for use as vaccine candidates. When rabbit polyclonal antibodies against the product of the DNA vaccine containing the ompW gene were tested in western blots with crude OMPs and recombinant OmpW, a strong reaction was observed against both. A putative signal peptide sequence of 21 residues at the $\mathrm{N}$-terminus of the OmpW protein has been predicted through analysis of the sequence of the ompW gene. As a secreted protein, mature OmpW is released and the signal peptide cleaved off after translocation (Movva et al. 1980, Jalajakumari \& Manning 1990). This explains the lower molecular weight of the mature OmpW in the crude OMPs compared to that of the recombinant OmpW (Fig. 2, Lanes 1, 2 and 3). The antibody reaction to both crude OMPs and recombinant OmpW proves that the DNA vaccine containing the omp $W$ gene of $V$. alginolyticus retained natural antigenicity. Therefore, this supports the use of the omp $W$ gene as a potential DNA vaccine candidate. Several bacterial Omp genes have been reported as being potential DNA vaccine candidates and can induce effective protection of the host, including those of $V$. harveyi (Wang et al. 2011), Salmonella typhimurium (Jang et al. 2011), Edwardsiella tarda (Sun et al. 2011) and Mannheimia haemolytica (Ayalew et al. 2010). In the present study, we demonstrated that an intramuscularly injected DNA vaccine containing the gene encoding for $V$. alginolyticus OmpW conferred significant protection to vaccinated fish challenged with $V$. alginolyticus.

Little is yet known about the tissue distribution, degradation and persistence of plasmid DNA in fish following DNA vaccination. Several reports have shown that DNA vaccines are able to reach other organs, such as kidney, spleen and gill, some days post-immunization, indicating that plasmid DNA can avoid local degradation at the administration site and in the blood plasma (Ayalew et al. 2010, Liang et al. 2011). In our study, although the PCR was performed using the ompW-F3 and ompW-R3 primers and the RNA template was treated with DNA-free ${ }^{\mathrm{TM}}$ DNase, it is still possible that pcDNA-omp $W$ vector contamination remained in the total RNA extracted from the tissues, as negative controls were not run for the reverse transcription step. The RT-PCR results therefore show that the pcDNA-ompW was distributed and/or expressed in several fish tissues including gill, head kidney, heart, liver, spleen and injection site muscle on 7 and $28 \mathrm{~d}$ post-vaccination. These results are in close agreement with those obtained by Liang et al. (2011).

We assessed the antibody levels generated against Vibrio alginolyticus OmpW in vaccinated and unvaccinated crimson snapper by ELISA. The results show that immunization of crimson snapper with the DNA vaccine containing the ompW gene induced significant protection against experimental challenge with $V$. alginolyticus. The DNA vaccine induced a significant antibody immune response in fish against the OmpW protein. The crimson snapper in control group I injected with pcDNA3.1 produced a higher serum antibody titre against the OmpW recombinant protein than those in control group II injected with PBS. This was possibly due to the polyclonal antibody characteristics of the fish serum used as the primary antibody source in the ELISA experiments. Comparison of the means of $\log _{2}$ antibody titres between the 2 control groups revealed their differences in titre were not statistically significant $(p>0.05)$. In this study, crimson snapper vaccinated with pcDNA-omp $W$ were protected against $V$. alginolyticus with an RPS of $92.53 \%$. However, a DNA vaccine encoding the ompU gene of $V$. harveyi provided protection in Scophthalmus maximus with an RPS of $51.5 \%$ (Wang et al. 2011). The difference in RPS reported for the 2 DNA vaccines may have been caused by differences in DNA sequence, bacterial virulence and immune response in the tested animals. Furthermore, other differences, including vaccine dose, the time which elapsed between vaccination and challenge, bacterial dose and inoculation method in the challenge experiment, and the fish species, could have contributed to the observed differences in the efficacy of the vaccines.

The DNA vaccine against infectious Vibrio alginolyticus is effective at protecting crimson snapper, but intramuscular injection is required and this makes the vaccine difficult to apply in the crimson snapper farming industry. More natural routes of delivery should be studied, such as oral administration or immersion, in order to determine efficient delivery methods for DNA vaccines in aquaculture situations. 
In conclusion, the ompW gene from Vibrio alginolyticus was cloned and expressed in E. coli, and proved to be a good candidate for a vaccine target against $V$. alginolyticus in crimson snapper. The DNA vaccine containing the ompW gene offers promise for the development of a protective vaccine for piscine vibriosis.

Acknowledgements. This work was supported by the National Program on Key Basic Research Project (No. 2009CB118704), the 973 Program Earlier Research Project (No. 2011CB111601), the National Science Foundation of Guangdong Province (No. S2011010000257), and the Science and Technology Planning Project of Guangdong Province (No. 2009B050700040) in the People's Republic of China. We thank all the people who have dedicated time to the experiments.

\section{LITERATURE CITED}

Austin B (1984) The future of bacterial fish vaccines. Vaccine 2:249-254

Ayalew S, Confer AW, Hartson SD, Shrestha B (2010) Immunoproteomic analyses of outer membrane proteins of Mannheimia haemolytica and identification of potential vaccine candidates. Proteomics 10:2151-2164

Boudinot P, Blanco M, de Kinkelin P, Benmansour A (1998) Combined DNA immunization with the glycoprotein gene of viral hemorrhagic septicemia virus and infectious hematopoietic necrosis virus induces doublespecific protective immunity and nonspecific response in rainbow trout. Virology 249:297-306

Cai SH, Wu ZH, Jian JC, Lu YS (2007) Cloning and expression of the gene encoding an extracellular alkaline serine protease from Vibrio alginolyticus strain HY9901, the causative agent of vibriosis in Lutjanus erythopterus (Bloch). J Fish Dis 30:493-500

- Cai SH, Yao SY, Lu YS, Wu ZH, Jian JC, Wang B (2010) Immune response in Lutjanus erythropterus induced by the major outer membrane protein (OmpU) of Vibrio alginolyticus. Dis Aquat Org 90:63-68

> Cai SH, Huang YC, Lu YS, Wu ZH, Wang B, Tang JF, Jian JC (2013) Expression and immunogenicity analysis of accessory colonization factor A from Vibrio alginolyticus strain HY9901. Fish Shellfish Immunol 34:454-462

Corbeil S, LaPatra SE, Anderson ED, Jones J, Vincent B, Hsu YL, Kurath G (1999) Evaluation of the protective immunogenicity of the N, P, M, NV and G proteins of infectious hematopoietic necrosis virus in rainbow trout Oncorhynchus mykiss using DNA vaccines. Dis Aquat Org 39:29-36

> Gatto NT, Dabo SM, Hancock RE, Confer AW (2002) Characterization of, and immune responses of mice to, the purified OmpA-equivalent outer membrane protein of Pasteurella multocida serotype A:3 (Omp28). Vet Microbiol 87:221-235

> Hong H, Patel DR, Tamm LK, Berg BVD (2006) The outer membrane protein OmpW forms an eight-stranded $\beta$-barrel with a hydrophobic channel. J Biol Chem 281: 7568-7577

> Hu YH, Sun L (2011) A bivalent Vibrio harveyi DNA vaccine induces strong protection in Japanese flounder (Para- lichthys olivaceus). Vaccine 29:4328-4333

Jalajakumari MB, Manning PA (1990) Nucleotide sequence of the gene, ompW, encoding a $22 \mathrm{kDa}$ immunogenic outer membrane protein of Vibrio cholerae. Nucleic Acids Res 18:2180

Jang MJ, Kim JE, Chung YH, Lee WB and others (2011) Dendritic cells stimulated with outer membrane protein A (OmpA) of Salmonella typhimurium generate effective anti-tumor immunity. Vaccine 29:2400-2410

$>$ Karalus RJ, Murphy TF (1999) Purification and characterization of outer membrane protein P6, a vaccine antigen of non-typeable Haemophilus influenzae. FEMS Immunol Med Microbiol 26:159-166

Karlsen C, Espelid S, Willassen NP, Paulsen SM (2011) Identification and cloning of immunogenic Aliivibrio salmonicida Pal-like protein present in profiled outer membrane and secreted subproteome. Dis Aquat Org 93:215-223

> Khushiramani R, Girisha SK, Karunasagar I, Karunasagar I (2007) Cloning and expression of an outer membrane protein ompTS of Aeromonas hydrophila and study of immunogenicity in fish. Protein Expr Purif 51:303-307

> Kumar SR, Parameswaran V, Ahmed VP, Musthaq SS, Hameed AS (2007) Protective efficiency of DNA vaccination in Asian seabass (Lates calcarifer) against Vibrio anguillarum. Fish Shellfish Immunol 23:316-326

Li H, Ye MZ, Peng B, Wu HK and others (2010a) Immunoproteomic identification of polyvalent vaccine candidates from Vibrio parahaemolyticus outer membrane proteins. J Proteome Res 9:2573-2583

Li N, Yang Z, Bai J, Fu X, Liu L, Shi C, Wu S (2010b) A shared antigen among Vibrio species: outer membrane protein-OmpK as a versatile vibriosis vaccine candidate in orange-spotted grouper (Epinephelus coioides). Fish Shellfish Immunol 28:952-956

> Liang HY, Wu ZH, Jian JC, Huang YC (2011) Protection of red snapper (Lutjanus sanguineus) against Vibrio alginolyticus with a DNA vaccine containing flagellin flaA gene. Lett Appl Microbiol 52:156-161

Liu R, Chen J, Li K, Zhang X (2011) Identification and evaluation as a DNA vaccine candidate of a virulenceassociated serine protease from a pathogenic Vibrio parahaemolyticus isolate. Fish Shellfish Immunol 30: 1241-1248

Ma ZN, Zheng L, Lin HM, Zheng YQ, Tang FX, Shi XA, Guo YH (2011) Preparation and identification of OmpW monoclonal antibodies. Chin J Cell Mol Immunol 27: 982-984 (in Chinese)

- Movva NR, Nakamura K, Inouye M (1980) Amino acid sequence of the signal peptide of ompA protein, a major outer membrane protein of Escherichia coli. J Biol Chem 255:27-29

Nandi B, Nandy RK, Sarkar A, Ghose AC (2005) Structural features, properties and regulation of the outermembrane protein W (OmpW) of Vibrio cholerae. Microbiology 151:2975-2986

> Prado ME, Dabo SM, Confer AW (2005) Immunogenicity of iron-regulated outer membrane proteins of Pasteurella multocida A:3 in cattle: molecular characterization of the immunodominant heme acquisition system receptor (HasR) protein. Vet Microbiol 105:269-280

> Qian R, Chu W, Mao Z, Zhang C, Wei Y, Yu L (2007) Expression, characterization and immunogenicity of a major outer membrane protein from Vibrio alginolyticus. Acta Biochim Biophys Sin (Shanghai) 39:194-200

Sengupta DK, Sengupta TK, Ghose AC (1992) Major outer 
membrane proteins of Vibrio cholerae and their role in induction of protective immunity through inhibition of intestinal colonization. Infect Immun 60:4848-4855

Sommerset I, Krossoy B, Biering E, Frost P (2005) Vaccines for fish in aquaculture. Expert Rev Vaccines 4:89-101

Sun Y, Liu CS, Sun L (2011) Comparative study of the immune effect of an Edwardsiella tarda antigen in two forms: subunit vaccine vs DNA vaccine. Vaccine 29: 2051-2057

Thompson JD, Gibson TJ, Plewniak F, Jeanmougin F, Higgins DG (1997) The CLUSTAL_X windows interface: flexible strategies for multiple sequence alignment aided by quality analysis tools. Nucleic Acids Res 25: 4876-4882

Touw DS, Patel DR, van den Berg B (2010) The crystal structure of OprG from Pseudomonas aeruginosa, a potential channel for transport of hydrophobic molecules across the outer membrane. PLoS ONE 5:e15016

Vazquez-Juarez RC, Gomez-Chiarri M, Barrera-Saldana H, Hernandez-Saavedra N, Dumas S, Ascencio E (2005)

Editorial responsibility: Catherine Collins, Aberdeen, UK
Evaluation of DNA vaccination of spotted sand bass (Paralabrax maculatofasciatus) with two major outermembrane protein-encoding genes from Aeromonas veronii. Fish Shellfish Immunol 19:153-163

Wang Q, Chen J, Liu R, Jia J (2011) Identification and evaluation of an outer membrane protein OmpU from a pathogenic Vibrio harveyi isolate as vaccine candidate in turbot (Scophthalmus maximus). Lett Appl Microbiol 53: $22-29$

Zhang J, Cai Z, Huang L (2006) Population genetic structure of crimson snapper Lutjanus erythropterus in East Asia, revealed by analysis of the mitochondrial control region. ICES J Mar Sci 63:693-704

Zhang C, Yu L, Qian R (2007) Characterization of OmpK, GAPDH and their fusion OmpK-GAPDH derived from Vibrio harveyi outer membrane proteins: their immunoprotective ability against vibriosis in large yellow croaker (Pseudosciaena crocea). J Appl Microbiol 103: 1587-1599

Submitted: December 5, 2012; Accepted: May 7, 2013

Proofs received from author(s): September 4, 2013 